\title{
A new Automatic Gas-Pump
}

This content has been downloaded from IOPscience. Please scroll down to see the full text. 1903 Proc. Phys. Soc. London 19270

(http://iopscience.iop.org/1478-7814/19/1/326)

View the table of contents for this issue, or go to the journal homepage for more

Download details:

IP Address: 139.184.14.159

This content was downloaded on 01/10/2015 at 06:55

Please note that terms and conditions apply. 


\section{A new Automatic Gas-Pump.}

$$
\text { By C. E. S. Phillips*. }
$$

This apparatus is constructed upon a plan which enables the pump, when once set in operation, to continue automatically and to produce as perfect a Torricellian vacuum as is possible.

It has been devised with a view to providing a comparatively portable machine suitable for special laboratory work or for researches requiring prolonged pumping, and consists of three distinct parts, viz. :- a small motor-driven mechanical pump, a four-way control valve, and a modified Toepler apparatus by which the final racuum is obtained. The action is as follows:-A vessel (say a Röntgen-riay lamp) baving been sealed on to the Toepler pump, the motor is set in motion, and a racuum produced in the whole apparatus equivalent to within about 5 inch of the barometric column.

The mercury now fills the lower chamber L (fig. 1) of the Toepler and completes an electrical circuit, which includes an electromagnet capable of so moving the controlling valve that it allows air at atmospheric pressure to enter and drive the mercury slowly into the upper chamber $U$. 'The Toepler pump operates in the usual manner. At the instant the quantity of mercury, moring as described, diminishes in L, the circuit just completed is broken, but the mercury soon accumulating in the trap $\mathrm{T}$ "makes" a second eircuit which moves the slider of the valve lack to its original position. The chamber is thus connected with the mechanical pump, the mercury falls, and the cycle is repeated automatically.

The gas removed by the Toepler would accumulate in the trap $T$ were it not that the mechanical pump is periodically comnected directly therewith. This is achieved by the control valve, when permitting air to enter $L$ also placing the mechanical pump in communication with the trap. The pressure in $\mathrm{T}$ is thus kept fairly constant, and the difference between it and that within the Toepler-pump head may at

* Read April 22, 1904. 
any moment he observed by mensuring the height of mercury in the capillary-fall tube $\mathrm{C}$.

The control device consists esientially of a hollow slider moving over a smooth flat betl, and covering or uncovering

Fig. 1.

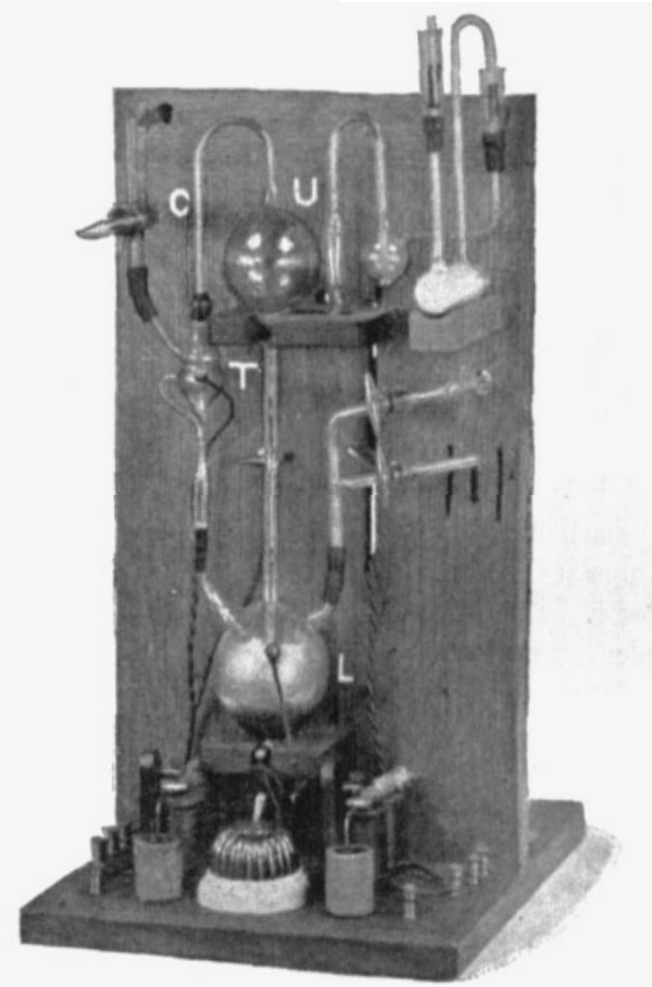

ports in the same manner as an ordinary slide-valve, but since the travel of this slider $S$ (fig. 2) is only one-eighth of an inch many devices are possible for actunting it; an electromagnet appears very suitable.

Two relays are introduced, one into ench circuit, in ordor that the current which operates the control-valve may be broken at external mercury cups. 
In the circuit, the completion of which moves the slider into the position for allowing air to enter $\mathrm{L}$, the action of the relay is retarded, for the purpose of enabling the mercury in the Toepler pump to remain in the lower chamber during a distinct interval of time before ascending.

Fig. 2.

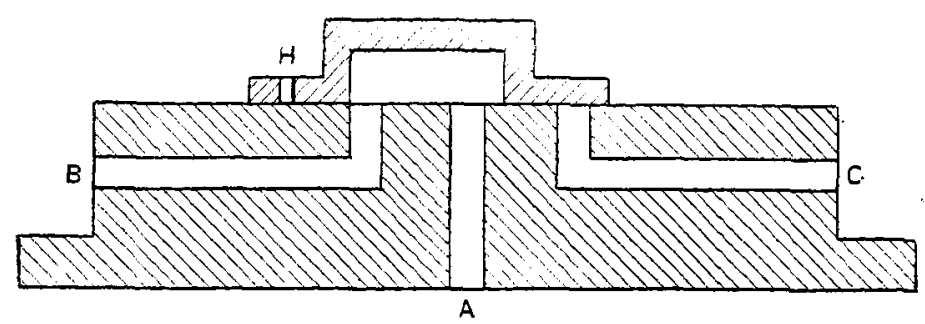

A communicates with the mechanical pump.

B " " lower chamber L.

C " " $\quad$ " the trap $T$.

A small hole $\mathrm{H}$ bored through the slider-flange ensures that the inrush of air into the lower chamber may be checked, and the upward movement of the mercury therefore take place slowly. The ideal conditions for efficiently working the Toepler pump are therefore attained, for the mercury rises slowly, sweeping out before it very efficiently the gas which fills the upper clamber; on the other hand, it falls rapidly (so that no time may be lost) and remains in the lower chamber for a fixed period before again ascending.

Experiment has shown that the apparatus is fairly rapid in its action. Careful tests mder specific conditions are in progress, but not yet sufficiently complete for publication. In a preliminary trial, however, the capacity of the chamber $\mathrm{U}$ being 160 c.c., 5 lbs. of mercury were raised three times per minute, with the result that a Röntgen-ray bulb of 200 c.c. capacity was exhausted in half-an-hour. The glass work is easily removable for cleaning or repairs, and the wood supports fitted with adjustable brackets. The height of the complete apparatus is 18 inches. 